\title{
ROTAS TECNOLÓGICAS DE APROVEITAMENTO DE RESÍDUOS AGRÍCOLAS, DESTINADAS À GERAÇÃO DE ENERGIA
}

\author{
R.R.BATISTA ${ }^{1}$, T. S. LIRA ${ }^{2}$, M.S. BACELOS ${ }^{2}$, G.L.D. CHAVES ${ }^{2}$, L.S. ARRIECHE ${ }^{2}$ \\ ${ }^{1}$ Aluno do Mestrado em Energia, Universidade Federal do Espírito Santo \\ ${ }^{2}$ Professor, Universidade Federal do Espírito Santo, Departamento de Engenharias e Tecnologia \\ E-mail para contato: renatorochabatista@gmail.com
}

\begin{abstract}
RESUMO - O uso de resíduos agrícolas como fonte de bioenergia tem despertado crescente interesse no setor de agroenergia. Este trabalho aborda o aproveitamento das cascas do cacau e café pelas tecnologias de biodigestão anaeróbia, pirólise e combustão direta. Realiza-se a síntese estrutural para a obtenção de energia elétrica por meio de árvores de estado. Combinam-se elementos estruturais atinentes a cada rota química, para a formação dos ramos das árvores. A otimização estrutural é conduzida pelo método heurístico. As rotas tecnológicas promissoras foram: biodigestão anaeróbia em batelada para a casca de cacau; e para a casca de café, a pirólise precedida de peletização. A representação do problema pela sistemática da Engenharia de Processos mostrou-se uma metodologia promissora para a valoração energética de resíduos de frutas.
\end{abstract}

\section{INTRODUÇÃO}

A utilização de biomassa proveniente de resíduos agrícolas vem se destacar como alternativa promissora num contexto de crise energética. Essa crise, por sua vez, vem ocorrendo devido à ineficiência da oferta de energia proveniente das principais fontes energéticas convencionais - petróleo e derivados; e sobretudo, devido à queda dos níveis dos reservatórios de água responsáveis pela geração de hidroeletricidade.

O setor elétrico do Brasil se encontra em crise, devido à dificuldades significativas de infraestrutura além de características sazonais, devido á origem de sua hidroeletricidade. No período de secas o risco de interrupção de energia é maior. Com base nesse dado, o governo brasileiro está desenvolvendo políticas para o incentivo à instalação de termoelétricas, cuja fonte energética possa ser a biomassa (COELHO, et al., 2002).

É imperativo a adoção de políticas para adoção de empreendimentos para geração de energia a partir da biomassa. Embora seja considerado um desafio em termos de retorno econômico do investimento a curto prazo, se justifica; pois segundo Cunha, et al., 1989, a biomassa apresenta baixo teor de enxofre. Além disso, segundo Ingham, 1999, o uso da biomassa 


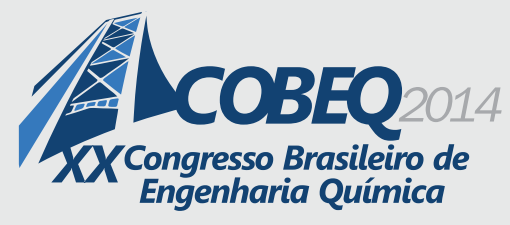

19 a 22 de outubro de 2014
Florianópolis/SC

tem outro aspecto ambiental favorável, devido ao fato da emissão de dióxido de carbono $\left(\mathrm{CO}_{2}\right)$ proveniente da queima da biomassa na atmosfera geralmente ser compensada pela absorção dele, quando do incentivo ao reflorestamento.

Em vista do aproveitamento energético, ainda ser aquém do potencial existente por parte dos resíduos agrícolas, florestais e sólidos urbanos; este artigo objetiva enfatizar o aproveitamento energético dos resíduos casca de café e casca de cacau, como exemplos de resíduos agrícolas. A priori, são analisados os fundamentos das tecnologias de combustão direta, pirólise e biodigestão anaeróbia. Com a técnica da busca exaustiva são elaborados os respectivos ramos de cada árvore de estado para os resíduos do tipo: casca do café e do cacau. A otimização estrutural e tecnológica é realizada por meio da aplicação das técnicas heurísticas. Os resultados obtidos são as respectivas rotas tecnológicas promissoras escolhidas para cada resíduo agrícola estudado.

\section{METODOLOGIA}

A metodologia se baseia conforme pesquisa de cunho documental. A etapa de síntese das árvores de estado baseia-se na interpretação de dados técnicos de caracterização residual e tecnológica. Por meio do método da busca exaustiva, elabora-se a sequência de etapas de processo para cada ramo das árvores de estado. Esta, por sua vez, consiste em gerar todas as combinações possíveis dos elementos do problema, ao percorrer sucessivamente todos os ramos da árvore (PERLINGEIRO, 2005). O projeto de processo pode ser visualizado da seguinte forma:

- Projeto: problema de otimização - enunciado definido com métodos sistemáticos de resolução;

- Problema: subdividido em nível tecnológico (definição de rota química), nível estrutural (síntese) e nível paramétrico (análise).

A metodologia do trabalho é direcionada a avaliar o problema de síntese a nível tecnológico e estrutural. A otimização baseia-se na aplicação de técnicas heurísticas. A abordagem de um processo químico pode ser subdividida em representação e resolução (PERLINGEIRO, 2005). A representação do tipo árvore de estados demonstra todas as possíveis rotas tecnológicas para o aproveitamento dos resíduos. A resolução, por sua vez, visa obter a solução ótima do problema orientado pela árvore de estados, pela aplicação de técnicas heurísticas.

Na Figura 1 tem-se a representação do que se conhece por árvore de estado de processos. É possível abranger o máximo de possibilidades de rotas tecnológicas (químicas), ou seja, soluções possíveis sem repetições e sem o risco de se omitir a solução ótima. Em relação às possibilidades de rotas tecnológicas, cabe mencionar as seguintes etapas indispensáveis para a realização das vias químicas: Para a realização da via química de biodigestão anaeróbia é indispensável o prétratamento químico por adição de solução básica; para a via química de pirólise é indispensável a presença de um equipamento reator de leito fixo, além da compactação (pirólise ou 
briquetagem); e para a via de combustão direta, um equipamento do tipo caldeira de grelha fixa.

A técnica de otimização heurística utiliza um conjunto de regras, ordenadas ou não, formando uma base intuitiva para a tomada de decisão. Para tanto, é de esperar a ocorrência de conflitos entre as regras elaboradas e a possibilidade de serem encontradas diferentes soluções conforme o critério utilizado para priorizá-las, o que permite caracterizar esta metodologia como subjetiva. Com a finalidade da proposição da solução mais próxima da solução ótima, é de suma importância o conhecimento adquirido na prática industrial ou através de simulações e análises de processo, que por sua vez se verifiquem concordantes com a observação experimental (CARVALHO, 1995).

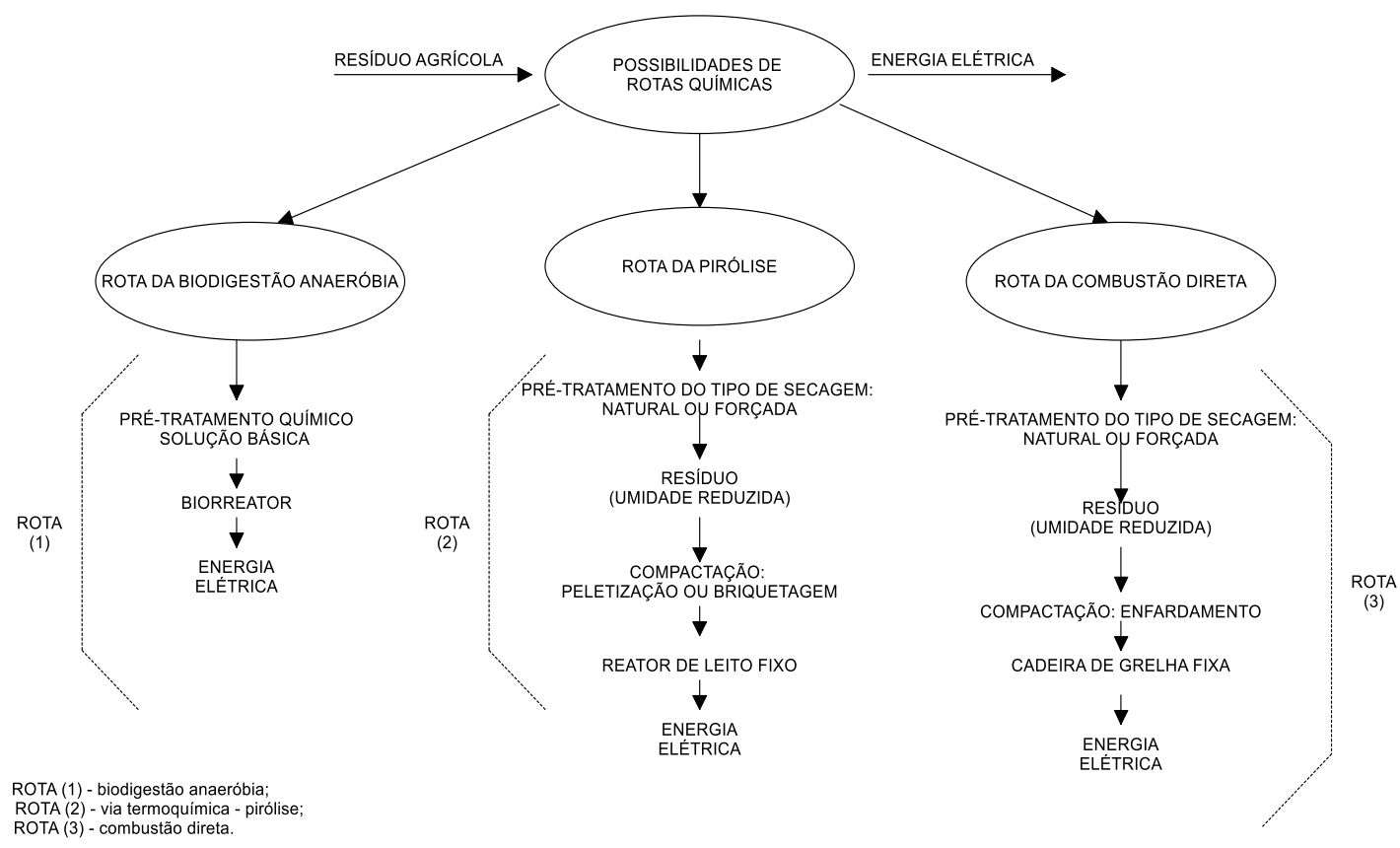

Figura 1 - O problema do projeto de processos representado por uma Árvore de Estados. (Rota tecnológica 1: via química da Biodigestão anaeróbia, rota tecnológica 2: via química da pirólise, rota tecnológica 3: via química da combustão direta).

\section{RESULTADOS}

\section{Representação por Árvores de Estado de processos químicos}

Mediante as possibilidades de vias químicas, para aproveitamento energético dos resíduos estudados, assim como das possibilidades de combinações entre as etapas de beneficiamento e conversão química, são elaboradas as possíveis vias tecnológicas.

Com a aplicação da sistemática de elaboração das árvores de estado, conforme 
esquematizado pela Figura 1, são elaboradas para cada resíduo uma árvore de estados. De acordo com os aspectos técnicos inerentes à caracterização residual da casca do cacau e do café; são apresentados as seguintes árvores de estado de processo, assim como a respectiva rota tecnológica escolhida para cada resíduo.

\section{Árvore de Estado - Casca do cacau}

Mediante a caracterização residual da casca de cacau, tem-se a apresentação das múltiplas rotas químicas e estruturais, por meio dos ramos da árvore de estados proposta, conforme a Figura 2.

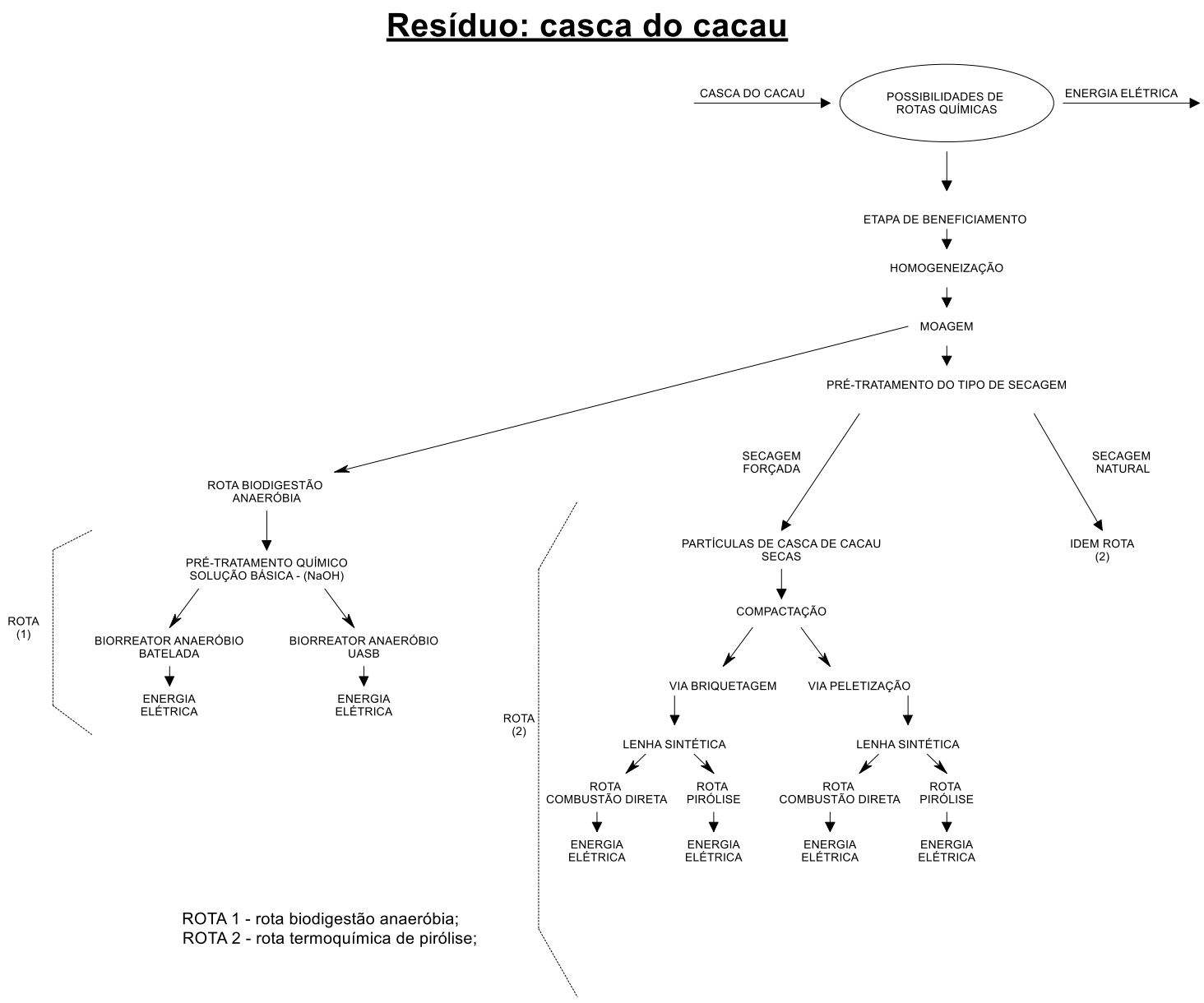

Figura 2 - Árvore de Estado de Processo - Casca do cacau. 


\section{Rota química promissora - Casca do cacau}

As regras heurísticas para escolha das vias de rotas químicas foram avaliadas, mediante as características principais do resíduo da casca de cacau. Conforme a Figura 3 tem-se a rota tecnológica escolhida.

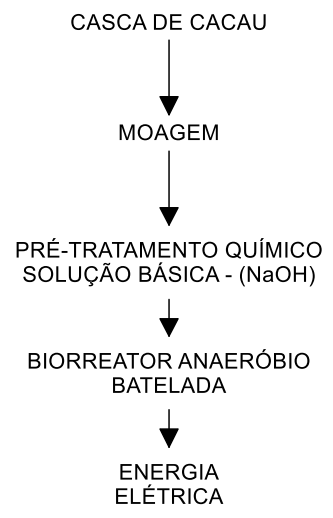

Figura 3 - Rota tecnológica promissora da casca do cacau

Com base na análise das características da casca de cacau, assim como da argumentação da árvore de estado proposta, nota-se que a alternativa viável é destiná-lo para a via de rota tecnológica da biodigestão anaeróbia. Como justificativa, tem-se que:

- O pré-tratamento por secagem e por compactação não são relevantes para esse tipo de caracterização residual, devido ao fato da casca do cacau ser de biodegradabilidade orgânica favorável á realização da biodigestão anaeróbia, segundo (GONZALES, et al., 2013). Dessa forma, sob condições ambientais, por ser um resíduo perecível, justifica-se seu aproveitamento por meio de uma tecnologia cuja aplicação seja adequada nas proximidades da lavoura. Dessa forma, opta-se pela via biológica do tipo biodigestão anaeróbia.

- Em relação ao equipamento conversor, em vista das duas possibilidades - biorretator batelada e biorreator de manta de lodo e fluxo ascendente - optou-se pela presença do equipamento do tipo reator batelada. Esse equipamento é mais apropriado para carga orgânica de matéria-prima em pequenas quantidades, sem necessidade de fluxo de alimentação contínuo, para a boa operacionalidade do equipamento. Além disso, como condição operacional têm-se a temperatura de operação em torno de $34^{\circ} \mathrm{C}$ e pressão de 1 atmosfera.

Dessa forma, mediante o exposto, a tecnologia de biodigestão anaeróbia em reator batelada se mostrou mais adequado à finalidade proposta. 


\section{Árvore de Estado - Casca do café}

Mediante a caracterização residual da casca de café, tem-se a apresentação das múltiplas rotas químicas e estruturais, por meio dos ramos da árvore de estados proposta, conforme a Figura 4.

Resíduo: casca do café

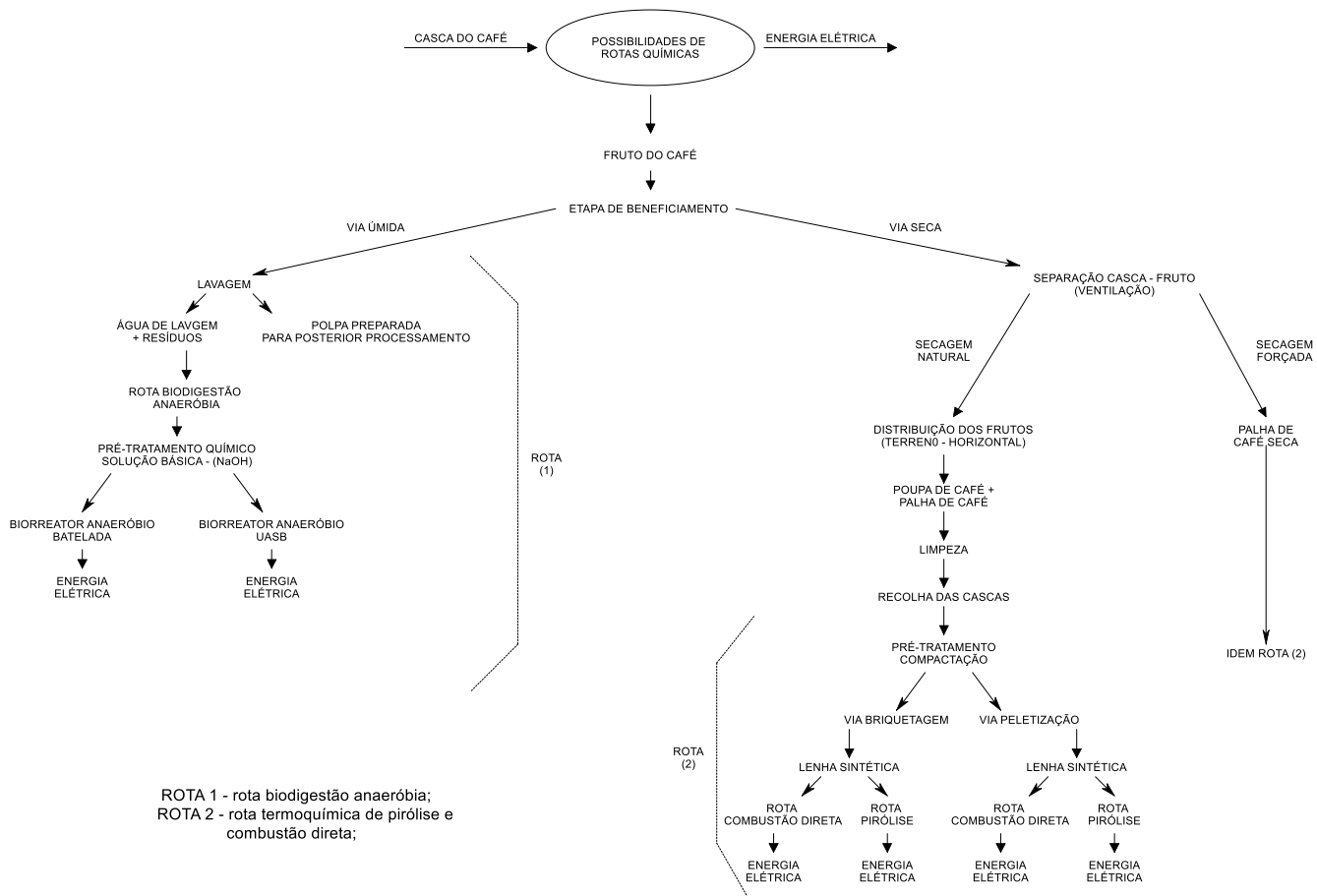

Figura 4 - Árvore de Estado de Processo - Casca do café

Acerca da heterogeneidade da matéria-prima residual assim como o conhecimento prévio das operações unitárias permitiram a elaboração da multiplicidade de rotas tecnológicas para cada árvore de estado de processos. Mediante às inúmeras combinações possíveis para se converter a matéria prima em produto de interesse destaca-se a contribuição do método heurístico. A vantagem da aplicação do método heurístico está correlacionada à proposta de metodologia do artigo em questão. Desta forma, segundo Carvalho, 1995, a conveniência e a aplicabilidade dos métodos heurísticos decorrem da simplicidade e de sua grande capacidade em pesquisar e selecionar as melhores sequências, diante das combinações possíveis.

\section{Rota tecnológica promissora para a casca do café}

As regras heurísticas para escolha de uma das vias de rotas tecnológicas possíveis foram avaliadas, mediante as características principais do resíduo da casca de café. Conforme a Figura 5 tem-se a rota tecnológica escolhida. 


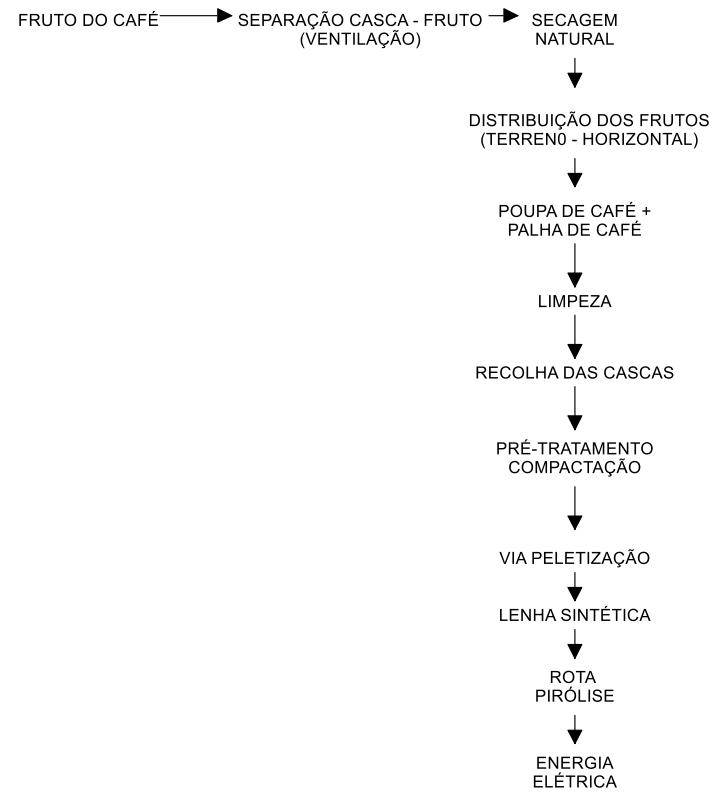

Figura 5 - Rota tecnológica promissora da casca do café

Com base na análise das características da casca de cacau, assim como da argumentação da árvore de estado proposta, nota-se que a alternativa viável é destiná-lo para a via de rota tecnológica da pirólise, precedida de compactação por peletização. Como justificativa, tem-se que:

- No que diz respeito à etapa de beneficiamento, seleciona-se a via seca para separação dos frutos em relação à palha do café. Os frutos do café são dispostos num terreiro horizontal, o que favorece a secagem do tipo natural. Isso se dá devido à alta superfície de contato da palha de café em relação às condições ambientais e teor de umidade de apenas 8,86\% em base úmida (ORSINI, 2012). Além disso, não há dependência de recurso hídrico para separação do resíduo casca de café em relação ao fruto (polpa). As características de alto teor de fibras e baixa biodegradabilidade orgânica, não justifica a escolha da biodigestão anaeróbia. Dessa forma, a casca do café apresenta maior tendência de aplicação nas tecnologias de alta temperatura, a pirólise e combustão direta por exemplo. Em vista da palha de café apresentar granulometria com diâmetro menor do que 5-10 mm, justifica-se a realização da técnica de compactação por peletização conforme Werther, 2000.

- O poder calorífico superior da palha de café de 23,64 MJ/Kg (PCS) (ORSINI, 2012), justifica a aplicação da tecnologia de conversão química do tipo pirólise. Para tanto, se faz necessário equipamento reator com temperatura em torno de $700^{\circ} \mathrm{C}$.

\section{CONCLUSÃO}

A utilização do método heurístico, para a realização da otimização estrutural e tecnológica, possibilitou obter a rota tecnológica promissora a partir de cada árvore de estado proposta, de 
forma que; os principais resultados obtidos são: - rota da digestão anaeróbia precedida de prétratamento químico em solução básica como a rota tecnológica mais promissora para o resíduo da casca de cacau; - rota de conversão termoquímica do tipo pirólise precedida de compactação do tipo peletização se mostrou mais promissora para o resíduo da casca de café.

As rotas tecnológicas promissoras obtidas, basearam-se na utilização da síntese heurística como etapa independente da otimização rigorosa de cada sequência, através de modelagem matemática.

\section{AGRADECIMENTOS}

À Coordenação de Aperfeiçoamento de Pessoal de Nível Superior (CAPES) pela bolsa de mestrado.

\section{REFERÊNCIAS}

CARVALHO, C.A.C. Síntese e otimização de sequências de destilação utilizando simuladores comerciais. Dissertação. 1995. Universidade Estadual de Campinas. Campinas, 1995.

CARVALHO, C.A.C. Síntese e otimização de sequências de destilação utilizando simuladores comerciais. Dissertação. 1995. Universidade Estadual de Campinas. Campinas, 1995.

COELHO, S. T.; VARKULYA JR., A.; PALETTA, C. E. M.; GUARDABASSI, P.; MARTINS, O. S. Geração de energia da madeira de reflorestamento. Revista da Madeira. Curitiba, Ano 11, n. 65, p. 24-26,2002.

CUNHA, M. P. S. C.; PONTES, C. L. F.; CRUZ, I. A.; CABRAL, M. T. F. D.; CUNHA NETO, Z. B.; BARBOSA, A. P. R. Estudo químico de 55 espécies lenhosas para geração de energia em caldeiras. In: $3^{\circ}$ encontro brasileiro em madeiras e em estruturas de madeira: Anais, v. 2, p. 93121, São Carlos, 1989.

GONZALES, A.D.F.; VITAL, A.V.D.; LIMA, J.M.; RODRIGUES, M.B.S.; Desenvolvimento sustentável para o resgate da cultura do cacau baseado no aproveitamento de resíduos. Interfaces Científicas - Saúde e Ambiente - Aracaju. V.1.n². p.41-52. Fev. 2013.

INGHAM, J. M. Biomassa no mundo e no Brasil. In: Fontes não-convencionais de energia: as tecnologias solar, eólica e de biomassa. Organização e edição: Alexandre de A. Montenegro, 2. ed. Florianópolis: Editora da UFSC, 1999. 160 p.

ORSINI, R.D.R, Estudo do aproveitamento do resíduo da lavoura cafeeira como fonte de biomassa na produção de hidrogênio. 2012, Tese, Universidade do Estado de São Paulo, São Paulo, 2012.

PERLINGEIRO, C.A.G., Engenharia de processos - análise, simulação, otimização e síntese de processos químicos. Editora Blucher. 2005.

WERTHER, J., SAENGER, M., HARTGE, E. U., OGADA, T. E SIAGI, Z., "Combustion of agricultultural residues", Progress in Energy and Combustion Science, Vol. 26, pp 1- 27 (2000). 